\title{
Multilocular Radiolucency in the Body of Mandible: A Systematic Diagnostic Approach
}

\author{
Rohit B Gadda, Neha Patil, Rohini Salvi
}

\begin{abstract}
Multilocular radiolucencies are produced by multiple, adjacent, frequently coalescing and overlapping pathologic compartments in bone. A number of lesions produce multilocular radiolucencies of the jaws. These are more common in the mandible as compared to the maxilla. To help the practitioner arrive at a working (clinical) diagnosis through the differential diagnosis process a systematic approach is needed. We present a case of acanthomatous ameloblastoma of the mandible and the possible lesions considered in the differential diagnosis to arrive at a clinical diagnosis.
\end{abstract}

Keywords: Multilocular radiolucency, Ameloblastoma, Differential diagnosis.

How to cite this article: Gadda RB, Patil N, Salvi R. Multilocular Radiolucency in the Body of Mandible: A Systematic Diagnostic Approach. J Contemp Dent 2012;2(2):39-42.

Source of support: Nil

Conflict of interest: None declared

\section{INTRODUCTION}

Ameloblastoma is a true neoplasm of enamel organ type tissue which does not undergo differentiation to the point of enamel formation. It has been described very aptly by Robinson ${ }^{1}$ as being a tumor that is 'usually unicentric, nonfunctional, intermittent in growth, anatomically benign and clinically persistent'. It is the most common clinically significant odontogenic tumor. ${ }^{1}$ Its peak incidence is in the third to fourth decades of life and has an equal sex distribution. ${ }^{2}$ This tumor presents with several clinicoradiographic and histologic subtypes like follicular, plexiform, acanthomatous, basaloid and granular cell types. Follicular and plexiform are the commonly encountered variants accounting to 32.5 and $28.2 \%$ respectively, followed by the acanthomatous subtype with $12.1 \%{ }^{3}$

It usually exhibits aggressive behavior. It causes severe expansions of the cortical bones and may have high recurrence rate. It may cause mobility and displacement of teeth as well as root resorption. ${ }^{4,5}$

Purpose of this report is to present a case of acanthomatous ameloblastoma and to discuss differential diagnosis of similar lesions of the mandible.

\section{CASE REPORT}

A 31-year-old male patient presented with a painless swelling on left mandibular region since 2 months. There was no difficulty in opening mouth, chewing or articulating. There was no history of any discharge and paresthesia. Patient gave history of trauma to left mandible 1 year ago due to which he had similar swelling and mobility of teeth in the region for which he underwent extraction of three teeth from this region. The swelling subsided thereafter but again recurred because of another episode of trauma to the same region 2 months back. Past medical and family history of the patient was noncontributory. No abnormality was elicited on systemic examination.

Extraoral examination revealed facial asymmetry due to diffuse swelling on lower left side of the face extending from left corner of mouth to $2 \mathrm{~cm}$ anterior to angle of the mandible anteroposteriorly. Superoinferiorly, it was extended from middle third of the cheek till inferior border of mandible. Swelling was measuring $4 \times 4 \mathrm{~cm}$ in size approximately. Overlying skin was normal (Fig. 1). On palpation, it was bony hard and nontender with no local rise in temperature.

Intraoral examination revealed obliteration of buccal sulcus in the region of 34, 35, 36 and 37 with both buccal and lingual cortical expansion and 34, 35 and 36 were missing (Fig. 2). On palpation, the swelling was nontender and bony hard in consistency. There was no regional lymphadenopathy.

A panoramic radiograph was taken (Fig. 3), which showed large multilocular radiolucent lesions in the left side of the mandible, extending from apical region of 31 to apical

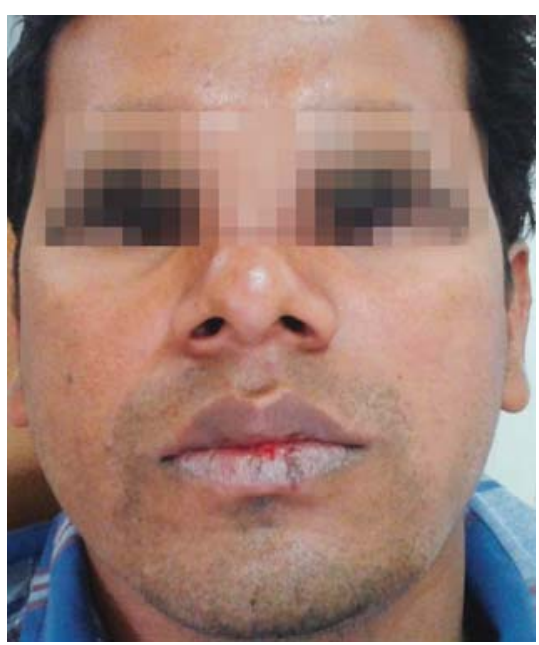

Fig. 1: Frontal view of face demonstrating facial swelling on left mandibular region 
region of mesial root of 37. Inferiorly radiolucent lesion was extending up to lower border of mandible with no obvious discontinuity in relation to the same. The lesion was well-defined with sclerotic borders and the margins were scalloped. Radiopaque septae were seen within the radiolucency. Mandibular canal could not be traced in anterior part of the lesion, but it was slightly displaced downward in the posterior aspect.

The occlusal radiograph (Fig. 4) revealed expansion of lingual cortical plate with loss of its continuity. Radiopaque septa were noted in the center of the lesion.

Considering the nature and location of the lesion, scalloped margins and presence of bony septae, the provisional diagnosis of ameloblastoma was given. Keratocystic odontogenic tumor (KOT) was considered in differential diagnosis.

Segmental resection of mandible was performed and specimen was sent for histopathological examination. Section showed tumor islands of odontogenic epithelium arranged in a variety of growth patterns like solid, cord, and some showing cystic degeneration and extensive

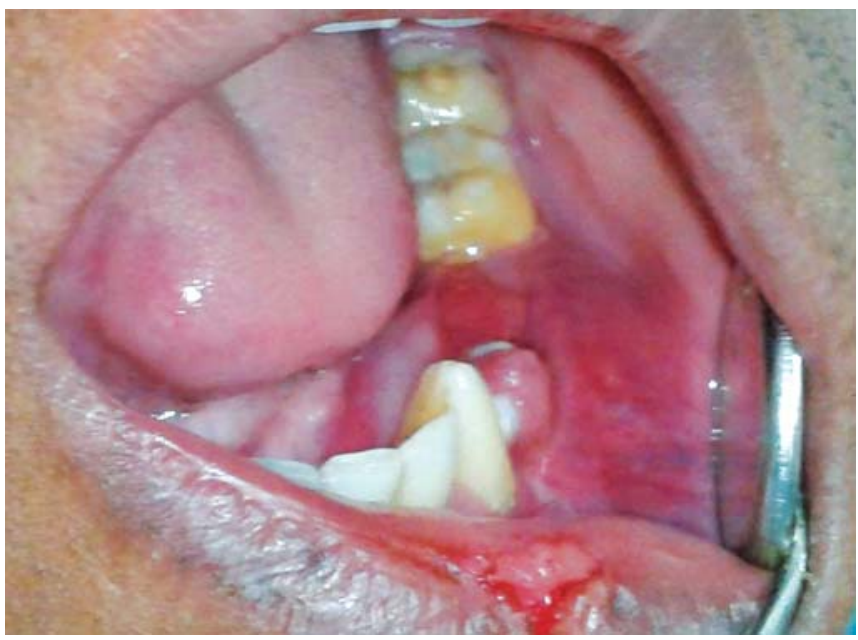

Fig. 2: Intraoral clinical photographs showing buccal and lingual cortical expansion in region of missing teeth 34,35 and 36

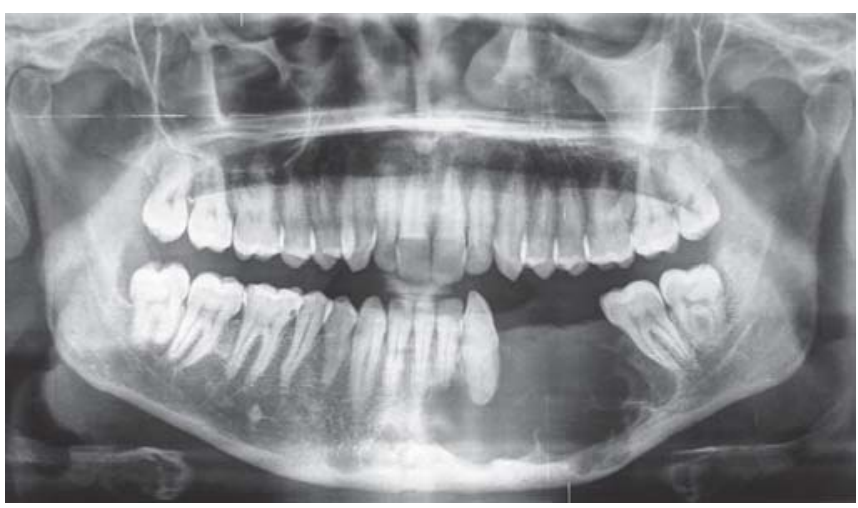

Fig. 3: Panoramic radiograph showing multilocular radiolucency in the left body of mandible

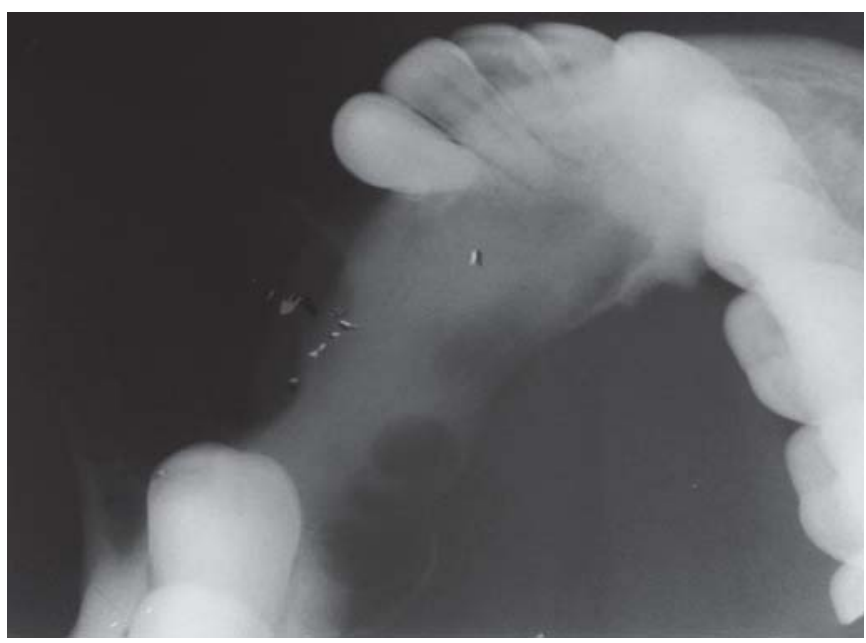

Fig. 4: Topographic occlusal of the left side mandible showing expansion of lingual cortical plate with presence of thick bony septa

squamous metaplasia. The peripheral cells resembled ameloblast-like cells with tendency for hyperplasia and pleomorphism. The collagenous connective tissue stroma supporting the tumor islands was sparse and devoid of inflammation. The overall picture was suggestive of acanthomatous ameloblastoma.

\section{DISCUSSION}

Many benign lesions cause multilocular radiolucencies in mandible and these can be divided into those of odontogenic and nonodontogenic origin. Lesions include ameloblastoma, radicular cyst, dentigerous cyst, odontogenic keratocyst (OKC), central giant cell granuloma, fibro-osseous lesions and osteomas (Table 1). ${ }^{6}$ The most common tumor of odontogenic origin is ameloblastoma, which develops from epithelial cellular elements and dental tissues in their various phases of development.

In the present case, considering the nature and location of the lesion, scalloped margins and presence of thick bony septae, a provisional diagnosis of ameloblastoma was given. Other common multilocular lesions were also considered in differential diagnosis and are listed in Table 1 . The multilocular cyst is the most frequently encountered pathologic multilocular radiolucency in the jaws, hence it was considered in differential diagnosis in present case. The most common is OKC which was ruled out because of expansion of buccal and lingual cortical plates, unilateral lesion not extending beyond the midline. OKC generally does not cause expansion of cortical plates and grows along the bone marrow, and extends to cross the midline. Central giant cell granuloma occurs in mandibular anterior region and radiographically has a multilocular appearance with illdefined wispy septae which emanate at right angles from 
Table 1: Differential diagnosis of multilocular radiolucencies of jaws features to rule them out in the present case

Multilocular radiolucencies

- Keratocystic odontogenic tumor

- Central giant cell granuloma

- Giant cell lesion of hyperparathyroidism

- Cherubism

- Odontogenic myxoma

- Aneurysmal bone cyst

- Metastatic tumors to the jaws

- Vascular malformations and central hemangioma of bone

- Ameloblastoma
Ruled out in present case because of

Expansion of buccal and lingual cortical plates

Unilateral lesion not extending beyond the midline

Location of lesion in mandibular posterior region

Thick bony septae in the lesion

Systemic examination was normal

Margins of the lesion was sclerotic

Age of the patient

Unilateral radiolucency involving body of the mandible

No appearance of tennis racket radiolucency

Pain was not a feature

No history or symptom of primary tumor

No gingival bleeding or localized pumping action of tooth

No history of bleeding after extractions from the region

No calcifications were seen in the lesion

Considered in provisional diagnosis of present case because of:

- Location of the lesion

- Multilocular appearance of radiolucency

- Scalloped margins

- Presence of thick bony septae the periphery of the lesion. Giant cell lesion of hyperparathyroidism occurs with systemic involvement. Cherubism is more commonly seen in children and presents as a bilateral multilocular radiolucency. Odontogenic myxoma presents as multilocular radiolucency presenting a tennis racket appearance due to presence of straight, thinetched septa. Aneurysmal bone cyst frequently involves persons less than 20 years of age and lesion is tender.

Intrabony metastatic jaw tumors may cause various radiographic appearances including multilocular radiolucencies, and the patient has a history of a primary malignancy elsewhere in the body.

Vascular malformations and central hemangioma of bone have been referred to as the great imitators because they can produce, so many different radiographic images including multilocular radiolucencies. Local hemorrhages may be evident around the cervices of the teeth encountered by the enlarging lesion. These teeth may also demonstrate a pumping action.

Of all swellings of the oral cavity, 9\% are odontogenic tumors, and within this group, ameloblastoma accounts for $1 \%$ of lesions. ${ }^{7-9}$ The WHO defines it as a locally_invasive polymorphic neoplasia that often has a follicular or plexiform pattern in a fibrous stroma. Its behavior has been described as being benign but locally aggressive. ${ }^{10,11}$ About $85 \%$ of ameloblastomas occur in the mandible, most often in the molar-ascending ramus area. About $15 \%$ of ameloblastomas occur in the maxilla, usually in the posterior regions. ${ }^{5}$

Ameloblastoma is observed as a radiolucent area, which may present in three different patterns. The most common is the soap bubble appearance. Another image is a honeycomb pattern, this being the second most common type. A third radiographic manifestation, which is very important in terms of a differential diagnosis, is the unilocular form. ${ }^{12}$

In choosing a treatment for ameloblastomas, the clinical type (solid, multicystic, unicystic, peripheral), localization, size of the tumor and age of the patient should be assessed. Resection should be as wide as possible to include healthy tissue, since recurrence is fairly common with this disease. $^{12-14}$

\section{REFERENCES}

1. Rajendran R. Cyst and tumors of odontogenic origin. In: Rajendran R, Sivapathasundharam B (Eds). Shafer's Textbook of Oral Pathology. Delhi: Elsevier 2010;271.

2. Gerzenshtein J, Zhang F, Caplan J, Anand V, Lineaweaver W. Immediate mandibular reconstruction with microsurgical fibula flap transfer following wide resection for ameloblastoma. J Craniofac Surg 2006;17(1):178-82.

3. Reichart PA, Philipsen HP, Sonner S. Ameloblastoma: Biological profile of 3677 cases. EurJ Cancer B Oral Oncol 1995;31:86-99.

4. Kahairi A, Ahmad RL, Wan Islah L, Norra H. Management of large mandibular ameloblastoma-a case report and literature reviews. Arch Orofac Sci 2008;3(2):52-55.

5. Neville BW, Damm DD, Allen CM, Bouquot JE. Odontogenic cysts and tumours. In: Neville BW, Damm DD, Allen CM, Bouquot JE (Eds). Oral and Maxillofacial Pathology (3rd ed). St Louis: Saunders 2009;702-11, 729.

6. Wood KN, Goaz PW. Differential diagnosis of oral and maxillofacial lesions (5th ed). St Louis: Mosby 1997;333.

7. Daley T, Wysocki G, Pringle G. Relative incidence of odontogenic tumors and oral and jaw cysts in a Canadian population. Oral Surg Oral Med Oral Pathol 1994;77: 276-80.

8. Odukoya O. Odontogenic tumors: Analysis of 289 Nigerian cases. J Oral Pathol Med 1995;24:454-57. 
9. Godwin T. A study of orofacial tumors in Nigerian children. J Oral Maxilofac Surg 1996;54:34-38.

10. Kramer I, Pindborg J, Shear M. Histological typing of odontogenic tumors. Berlin, Springer 1992.

11. Gold L, Upton GW, Marx RE. Standardized surgical terminology for the excision of lesions in bone: An argument for accuracy in reporting. J Oral Maxillofac Surg 1991;49: 1214-17.

12. Torres-Lagares D, Infante-Cossio P, Hernandez-Guisado JM, Gutierrez-Perez JL. Mandibular ameloblastoma. A review of the literature and presentation of six cases. Med Oral Patol Oral Cir Bucal 2005;10:231-38.

13. Gardner DG. A pathologist's approach to the treatment of ameloblastoma. J Oral Maxillofac Surg 1984;42:161-66.

14. Leider AS, Eversole LR, Barkin ME. Cystic ameloblastoma. A clinicopathologic analysis. Oral Surg 1985;60:624-30.

\section{ABOUT THE AUTHORS}

\section{Rohit B Gadda (Corresponding Author)}

Senior Lecturer, Department of Oral Medicine and Radiology MGM Dental College and Hospital, Navi Mumbai, Maharashtra, India e-mail: rohitgadda@gmail.com

\section{Neha Patil}

Senior Lecturer, Department of Oral Medicine and Radiology, MGM Dental College and Hospital, Navi Mumbai, Maharashtra, India

\section{Rohini Salvi}

Professor and Head, Department of Oral Medicine and Radiology, MGM Dental College and Hospital, Navi Mumbai Maharashtra, India 